\title{
Tungsten oxide-Au nanosized film composites for glucose oxidation and sensing in neutral medium
}

This article was published in the following Dove Press journal:

International Journal of Nanomedicine

15 April 2015

Number of times this article has been viewed

\author{
Maxime Gougis \\ Dongling $\mathrm{Ma}$ \\ Mohamed Mohamedi \\ INRS-Énergie, Matériaux et \\ Télécommunications, Varennes, \\ Québec, Canada
}

Correspondence: Mohamed Mohamedi INRS-Énergie, Matériaux et Télécommunications, 1650 Boulevard Lionel Boulet, Varennes, Québec, Canada $\mathrm{Tel}+|5| 4228683 \mid$

Fax + I 4509298102

Email mohamedi@emt.inrs.ca

\begin{abstract}
In this work, we report for the first time the use of tungsten oxide (WOx) as catalyst support for Au toward the direct electrooxidation of glucose. The nanostructured WOx/ $\mathrm{Au}$ electrodes were synthesized by means of laser-ablation technique. Both micro-Raman spectroscopy and transmission electron microscopy showed that the produced WOx thin film is amorphous and made of ultrafine particles of subnanometer size. X-ray diffraction and X-ray photoelectron spectroscopy revealed that only metallic Au was present at the surface of the WOx/ $\mathrm{Au}$ composite, suggesting that the WOx support did not alter the electronic structure of $\mathrm{Au}$. The direct electrocatalytic oxidation of glucose in neutral medium such as phosphate buffered saline ( $\mathrm{pH}$ 7.2) solution has been investigated with cyclic voltammetry, chronoamperometry, and square-wave voltammetry. Sensitivity as high as $65.7 \mu \mathrm{A} \mathrm{cm} \mathrm{cm}^{-2} \mathrm{mM}^{-1}$ up to $10 \mathrm{mM}$ of glucose and a low detection limit of $10 \mu \mathrm{M}$ were obtained with square-wave voltammetry. This interesting analytical performance makes the laser-fabricated WOx/Au electrode potentially promising for implantable glucose fuel cells and biomedical analysis as the evaluation of glucose concentration in biological fluids. Finally, owing to its unique capabilities proven in this work, it is anticipated that the laser-ablation technique will develop as a fabrication tool for chip miniature-sized sensors in the near future.
\end{abstract}

Keywords: $\mathrm{Au}$, tungsten oxide, nanostructures, pulsed laser deposition, glucose oxidation and sensing

\section{Introduction}

Owing to their abundance, low cost, and environmental friendliness, several metal oxides (MOx) $(\mathrm{M}=\mathrm{Ti}, \mathrm{W}, \mathrm{Mn}, \mathrm{Mo}, \mathrm{Sn}$, or $\mathrm{Ce}$ ) have wide applications in various electrochemical technologies, such as polymer electrolyte fuel cells, ${ }^{1}$ photoelectrochemical cells ${ }^{2,3}$ and energy-storage devices, ${ }^{4}$ and medical applications. Indeed, MOx exist in a highly oxidative state and are thus unlikely to lose further electrons to oxidation, which makes them more resistant to corrosion in electrochemical environments, such as those of polymer electrolyte fuel cells, compared with carbon. ${ }^{1}$ They can perform as supports to improve catalyst dispersion and its durability against sintering and particle aggregation. MOx can also promote certain electrocatalytic reactions via electronic effect or even function as cocatalysts via a bifunctional mechanism. In addition, several MOx possess high isoelectric points $(>9)$ and can be helpful to immobilize through electrostatic interactions enzymes with low isoelectric points, which helps to retain the bioactivity of the enzyme - an important issue for mediator-free enzymatic electrodes for biological fuel cells. ${ }^{5}$

The glucose electrooxidation reaction (GER) has generated much interest over the years. ${ }^{6}$ It has been extensively studied for applications in glucose-oxygen fuel cells, ${ }^{7}$ 
as well as for determining glucose concentrations, which is vital in clinical applications that require regular measurement of blood glucose levels, such as biosensors for diabetes, ${ }^{8}$ or in food processing and fermentation. ${ }^{9}$

$\mathrm{Au}$ is an attractive metal for GER because of its biological compatibility and because its oxidation potential in neutral and alkaline medium is more-negative compared to the other metals and therefore has been extensively examined. ${ }^{10}$ However, improved sensitivity associated with cost is needed for applying $\mathrm{Au}$ as an effective catalyst for GER. In order to overcome these problems, numerous approaches were sought toward the use of nanostructured Au in electrodes, in recent years. More recent promising approaches include $\mathrm{Au}$ nanoparticle-modified glassy carbon electrodes, ${ }^{11}$ Au nanoparticle/polyaniline composites, ${ }^{12}$ nanoporous Au surfaces, ${ }^{13}$ Au nanostructures on phosphorus-doped diamond-like carbon surfaces,${ }^{14}$ ordered Au nanowires fabricated by employing anodic aluminum oxide templates in combination with direct electrodeposition, ${ }^{15}$ carbon nanotubes (CNTs) coated with Au nanoparticles, ${ }^{16-18}$ and anodic fabrication of nanoporous Au films from pure Au in oxalic acid. ${ }^{19}$

In a new review of recent advances in nonenzymatic glucose sensors, ${ }^{20}$ it is shown that the combination of nanostructured metals and metal oxides offers larger surface area for the oxidation of glucose. In our previous publications, we reported the electrocatalytic performance toward GER of $\mathrm{Au}$ nanoparticles when combined with $\mathrm{CeO}_{2} \cdot{ }^{20,21}$ As compared to Au nanoparticles supported by $\mathrm{CNTs}$, the $\mathrm{Au}-\mathrm{CeO}_{2}$ system had much better performance in terms of glucose oxidation and sensing in neutral medium, such as $\mathrm{pH} 7.2$ phosphatebuffered saline (PBS) solution. Sensitivity as high as $57.5 \mu \mathrm{A} \mathrm{cm}^{-2} \mathrm{mM}^{-1}$ up to $10 \mathrm{mM}$ of glucose (far beyond the physiological level of 3-8 $\mathrm{mM}$ ) and a low detection limit of $10 \mu \mathrm{M}$ were obtained.

Tungsten oxide (WOx) is another material that is of great interest due to its application in several devices such as photoelectrochromic "smart" windows, optical devices, gas/humidity sensors, photocatalysts, ${ }^{22-26}$ and others like electrocatalyst support in polymer electrolyte fuel cells, ${ }^{1}$ anode for lithium ion batteries, ${ }^{27}$ or as a material electrode for supercapacitors. ${ }^{28}$

To the best of our knowledge, WOx has never been investigated as electrode material toward glucose oxidation or sensing. WOx alone is not active toward GER, but it can be an efficient catalyst support for Au nanoparticles. This work is thus the first to investigate and demonstrate the supporting electrocatalytic properties of WOx for Au toward GER, yielding a high detection sensitivity for glucose.
Both WOx and Au are synthesized using the pulsed laser deposition (PLD) technique. WOx is first deposited onto an electrically conductive and porous carbon-paper substrate (CP) (the current collector), which is the type of carbon paper used in several electrochemical devices. Afterwards, $\mathrm{Au}$ nanoparticles are deposited onto WOx. Such synthesized materials are first characterized with field emission scanning electron microscopy (FESEM), X-ray diffraction (XRD), X-ray photoelectron spectroscopy (XPS), microRaman spectroscopy, and transmission electron microscopy (TEM). Next, the electroactivity and sensing properties of the $\mathrm{WOx} / \mathrm{Au}$ system are investigated by cyclic voltammetry (CV), chronoamperometry, and square-wave voltammetry (SWV) electrochemical techniques in $\mathrm{pH}$ 7.2 PBS solution containing glucose concentrations varying from $10 \mu \mathrm{M}$ to $100 \mathrm{mM}$.

\section{Material and methods Material synthesis}

Both WOx and $\mathrm{Au}$ nanostructures were synthesized with PLD at room temperature by means of a pulsed krypton fluoride excimer laser ( $\lambda=248 \mathrm{~nm}$, pulse width $=17 \mathrm{~ns}$, and repetition rate $=50 \mathrm{~Hz}$ ) and a laser fluence of $4 \mathrm{~J} \mathrm{~cm}^{-2}$. A pure (99.95\%) W target (Kurt J. Lesker Co., ON, Canada) was ablated under $1.33 \mathrm{~Pa}$ of oxygen, and 20,000 laser pulses were used to deposit WOx onto an unheated CP (Toray). Subsequently, Au was deposited under vacuum onto WOx by ablating a pure $(99.99 \%)$ polycrystalline Au target (Kurt J. Lesker Co.) with 50,000 laser pulses. Before deposition, the PLD chamber was evacuated with a turbo pump $\left(2 \times 10^{-5}\right.$ Torr). In all cases, the target-to-substrate distance was set to $5 \mathrm{~cm}$. During deposition, the target was continuously rotated and translated so as to attain a uniform ablation over the whole target surface. A detailed description of the PLD setup and its working principles can be found elsewhere. ${ }^{29}$

\section{Material characterization}

The morphologies of the WOx and WOx/Au structures were examined by means of FESEM (JEOL-JSM-7600F) and TEM (JEOL-JEM-2100F operating at $200 \mathrm{kV}$ ).

The surface composition was studied by XPS via a VG Escalab 220i-XL equipped with an Al K $\alpha$ source (1486.6 eV). The anode was operated at $10 \mathrm{kV}$ and $20 \mathrm{~mA}$. The pass energy of the analyzer was fixed at $20 \mathrm{eV}$. All samples were analyzed with a spot size of $250 \mu \mathrm{m} \times 1,000 \mu \mathrm{m}$ located approximately in the center of the samples. A survey spectrum ranging from 0-1,300 eV was first acquired and then higher-resolution multiplex scan spectra of $\mathrm{W} 4 \mathrm{f}$ and $\mathrm{Au} 4 \mathrm{f}$ were obtained. 
Quantification of the elements was carried out with CasaXPS software (Casa Software Ltd.) by fitting the core level spectra after a Shirley background removal. The $\mathrm{C} 1 \mathrm{~s}$ core level peak at $284.6 \mathrm{eV}$, resulting from hydrocarbon contaminants at the surface, was used as an internal reference. All spectra have been recalibrated with respect to the $\mathrm{C} 1 \mathrm{~s}$ core level peak of adventitious carbon contamination.

The crystalline structure of all samples was determined by XRD using a Bruker D8 Advance diffractometer equipped with a $\mathrm{Cu} \mathrm{K} \alpha$ source. The diffractometer was operated at $40 \mathrm{kV}$ and $40 \mathrm{~mA}$. All diffractograms were acquired in the grazing incidence diffraction scan mode with an incident angle of $2^{\circ}, 2 \theta$ angular step size of $0.05^{\circ}$, and acquisition time of 5 seconds per step.

Micro-Raman spectroscopy was performed using the $514.5 \mathrm{~nm}(2.41 \mathrm{eV})$ laser radiation of an $\mathrm{Ar}^{+}$laser with a circular polarization. The laser beam was focused onto the sample to a spot size of $1 \mu \mathrm{m}$ in diameter (micro-Raman spectroscopy, Renishaw Imaging Microscope WireTM).

\section{Electrochemical measurements}

Before the electrochemical measurements, the surface of the WOx/Au working electrode was cleaned electrochemically by potential cycling in $0.5 \mathrm{M} \mathrm{H}_{2} \mathrm{SO}_{4}$. The electrochemical properties of the Au electrodes were investigated using $\mathrm{CV}$, chronoamperometry, and SWV in a deaerated pH 7.2 PBS solution (Sigma-Aldrich Co., St Louis, MO, USA) with glucose (D-(+)-glucose, American Chemical Society reagent grade; Sigma-Aldrich). All electrochemical measurements were conducted at room temperature using a three-compartment electrochemical cell with an $\mathrm{Ag} / \mathrm{AgCl}, 3 \mathrm{M} \mathrm{NaCl}$ reference electrode and a platinum coil as a counter electrode. Measurements and data acquisition were conducted with an Autolab potentiostat/galvanostat from Eco Chemie (Utrecht, the Netherlands).

\section{Results and discussion Characterization of tungsten oxide}

Figure $1 \mathrm{~A}$ and $\mathrm{B}$ are FESEM images at nominal magnification of $5,000 \times$ and $100,000 \times$ of WOx deposited in the presence of $1.33 \mathrm{~Pa}$ of oxygen on the carbon microfibers constituting the $\mathrm{CP}$ substrate. The images show a WOx layer of rough morphology.

Raman spectroscopy is a powerful tool for phase and structural analysis of materials. Micro-Raman spectrum of WOx films deposited onto CP shown in Figure 1C, is the typical signal of amorphous tungsten oxide ${ }^{30}$ and is similar to those of WOx deposited by PLD at $0.6 \mathrm{~Pa}$ of oxygen pressure using sintered $\mathrm{WO}_{3}$ as the ablated target, ${ }^{31}$ or to $\mathrm{WOx}$ deposited using $\mathrm{W}$ target in an oxidizing atmosphere (at $10 \mathrm{~Pa}$ of dry air)..$^{32}$ The spectrum shows three broad features in the $100-300 \mathrm{~cm}^{-1}, 300-550 \mathrm{~cm}^{-1}$, and $550-1,000 \mathrm{~cm}^{-1}$ regions. The Raman band at $210 \mathrm{~cm}^{-1}$ corresponds to $\mathrm{W}^{5+}-\mathrm{W}^{5+}$ vibrations and are expected in partially reduced $\mathrm{WO}_{3-\mathrm{x}}$ phases. ${ }^{33,34}$ The Raman bands at $275 \mathrm{~cm}^{-1}$ and $430-440 \mathrm{~cm}^{-1}$ correspond to the deformation vibrations of $(\mathrm{O}-\mathrm{W}-\mathrm{O})$ bonds and the band at $800 \mathrm{~cm}^{-1}$ corresponds to the stretching vibrations of $\mathrm{W}-\mathrm{O}$ bonds. ${ }^{35,36}$ It should be noted that XRD (not shown) did not show any peak related to metallic W.

The XPS wide survey spectrum (Figure S1) of the synthesized WOx on CP revealed the presence of only $\mathrm{C}, \mathrm{W}$, and $\mathrm{O}$ with a surface composition of $33.47 \%, 20.79 \%$, and $45.73 \%$, respectively. Figure 1D shows the high-resolution XPS spectrum of the $\mathrm{W} 4 \mathrm{f}$ region, which indicates that $\mathrm{W}$ species in the tungsten oxide film showed three oxidation states. The $\mathrm{W} 4 \mathrm{f}$ level of the sample can be deconvoluted into three doublets. The first one had the $\mathrm{W}_{4} \mathrm{f}_{7 / 2}$ line at a binding energy of $35.89 \mathrm{eV}$, which is assigned to $\mathrm{W}^{6+}$ species; the second doublet with the $\mathrm{W}_{7 / 2}$ line at $33.51 \mathrm{eV}$, ascribed to $\mathrm{W}^{5+}$ species; and the third doublet had a lower binding energy with the $\mathrm{W}_{7 / 2}$ at $32.42 \mathrm{eV}$ corresponding to $\mathrm{W}^{4+}$ species. ${ }^{37}$ The broad peak located around $40 \mathrm{eV}$ is attributed to $\mathrm{W} 5 \mathrm{p}_{3 / 2}$. These three oxidation states are the typical oxidation states found in $\mathrm{W}_{18} \mathrm{O}_{49}$ compound. ${ }^{38}$ The percentages of $\mathrm{W}^{6+}, \mathrm{W}^{5+}$, and $\mathrm{W}^{4+}$ species were $33.0 \%, 50.8 \%$, and $16.2 \%$, respectively.

TEM (Figure 2A and B) and high resolution (HR)-TEM (Figure 2C and D) images show that the WOx deposit is a film made of ultrafine nanoparticles of subnanometer size. In addition, a fully amorphous microstructure without any crystalline feature can be confirmed for the WOx deposit, according to the selected-area electron diffraction (SAED) pattern (Figure 2E), which shows a large and diffusive central spot indicative of the presence of an amorphous WOx phase, which is in agreement with Raman observations.

\section{Characterization of WOx/Au}

Figure 3 shows typical FESEM images at increasing magnifications of the Au film grown onto WOx. The Au film is shaped into ordered segments made of clusters of particles. The XRD profile shown in Figure 4A does not reveal peaks related to $\mathrm{W}$. The diffractogram is similar to that of polycrystalline $\mathrm{Au}$ - that is to say, the diffraction peaks at $2 \theta=38.2^{\circ}, 44.4^{\circ}, 64.6^{\circ}, 77.6^{\circ}$, and $81.7^{\circ}$, corresponding to (111), (200), (220), (311), and (222) reflections, respectively (JCPDS [Joint Committee on Powder Diffraction Standards] 

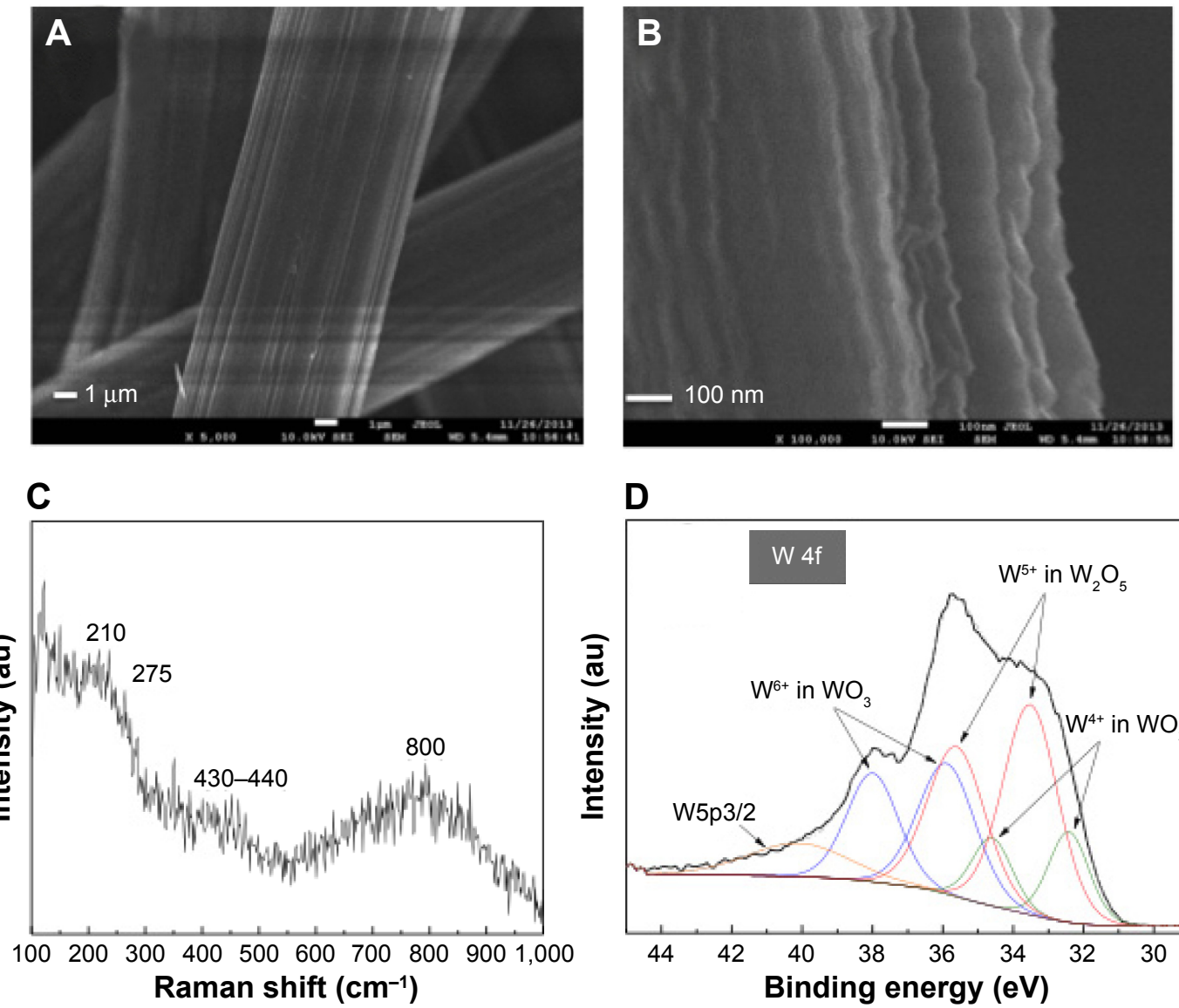

D

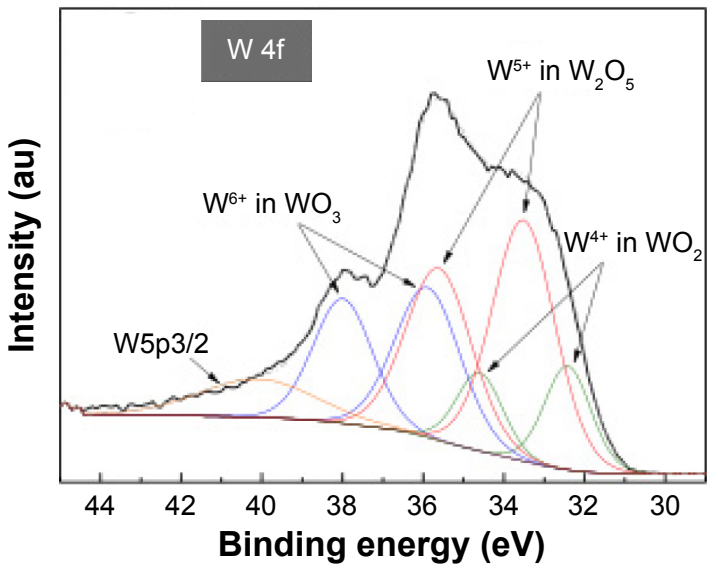

Figure I WOx deposited by PLD onto carbon paper substrate.

Notes: (A and B) FESEM images. (C) Micro-Raman spectrum. (D) High-resolution XPS spectrum of the W $4 \mathrm{f}$ region.

Abbreviations: FESEM, field emission scanning electron microscopy; PLD, pulsed laser deposition; WOx, tungsten oxide; XPS, X-ray photoelectron spectroscopy.

89-3,697). This indicates that only metallic Au is present. By using the Debye-Scherrer equation and the most intense (111) diffraction peak for $\mathrm{Au}$, the average crystallite size was estimated to be $36 \mathrm{~nm}$, whereas the lattice constant is equal to $0.408 \mathrm{~nm}$, close to theoretical calculations.

An XPS survey scan (Figure S2) of Au deposited onto WOx presents peaks only for $\mathrm{Au}, \mathrm{C}$, and $\mathrm{O}$, with a surface composition of $40.1 \%, 48.1 \%$, and $11.8 \%$, respectively. Note that no W component is detected at the surface of the WOx/ $\mathrm{Au}$ sample, which confirms the uniform coating of WOx by Au. High-resolution XPS spectrum in the Au 4f region of Au film grown onto WOx is shown in Figure 4B. The spectrum displays two $4 \mathrm{f}_{7 / 2}$ and $4 \mathrm{f}_{5 / 2}$ core levels whose maximum intensities are located at binding energies of $84.0 \pm 0.1$ and $87.6 \pm 0.1 \mathrm{eV}$. There is a $3.6 \pm 0.1 \mathrm{eV}$ energy difference between the $4 f_{7 / 2}$ and $4 f_{5 / 2}$ components, which indicates that $\mathrm{Au}$ was in the metallic state. ${ }^{39}$ No other chemical states of $\mathrm{Au}$ were identified, and satisfactory fitting of each core level peak was obtained using only one component with an asymmetric profile. Thus, XPS results are in accordance with those of XRD indicating that the chemical state of $\mathrm{Au}$ is not affected by the WOx support under the conditions of synthesis considered in this work.

Figure 5A-C show TEM and HR-TEM images of the PLD-deposited Au onto WOx. The images show that the morphology of Au is a mixture of well-separated more-or-less spherical nanoparticles and micelles-like Au particles. The particle size distribution over 133 particles (region indicated in the figure) revealed an average size of $8 \mathrm{~nm}$ (Figure 5D). As an indication, the average sizes for Au particles deposited under vacuum by PLD on different supports such as CNTs and $\mathrm{CeO}_{2}$ were $4.1 \mathrm{~nm}$ and $5.1 \mathrm{~nm}$, respectively. Therefore, under the conditions of synthesis considered in this work, it seems that WOx in the C/Au gives rise to larger particles of Au.

The synthesized WOx/Au sample was first characterized with $\mathrm{CV}$ in an argon-saturated solution of $0.5 \mathrm{M} \mathrm{H}_{2} \mathrm{SO}_{4}$ at a scan rate of $50 \mathrm{mV} \mathrm{s}^{-1}$ (Figure 6A). The $\mathrm{CV}$ profile exhibits the typical redox processes due to Au oxide formation within a 1.1-1.6 $\mathrm{V}$ potential range, and a reduction peak positioned at $0.94 \mathrm{~V}$ versus $\mathrm{Ag} / \mathrm{AgCl}$. An electroactive surface area 


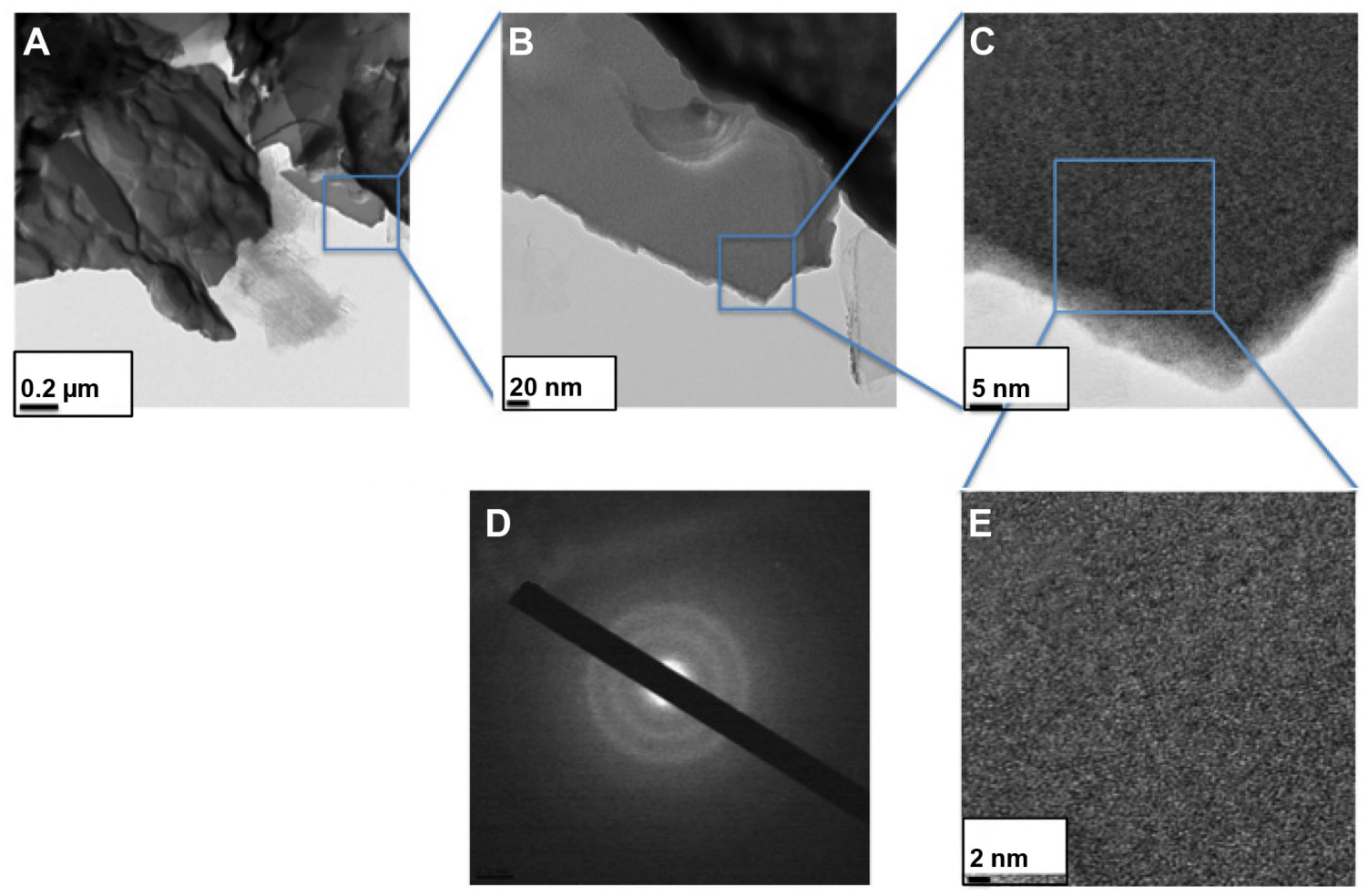

Figure 2 WOx deposited by PLD onto carbon paper substrate.

Notes: (A and B) TEM and (C and E) HR-TEM analyses. (D) SAED pattern.

Abbreviations: SAED, selected-area electron diffraction; HR-TEM, high-resolution transmission electron microscopy; PLD, pulsed laser deposition; TEM, transmission electron microscopy; WOx, tungsten oxide.
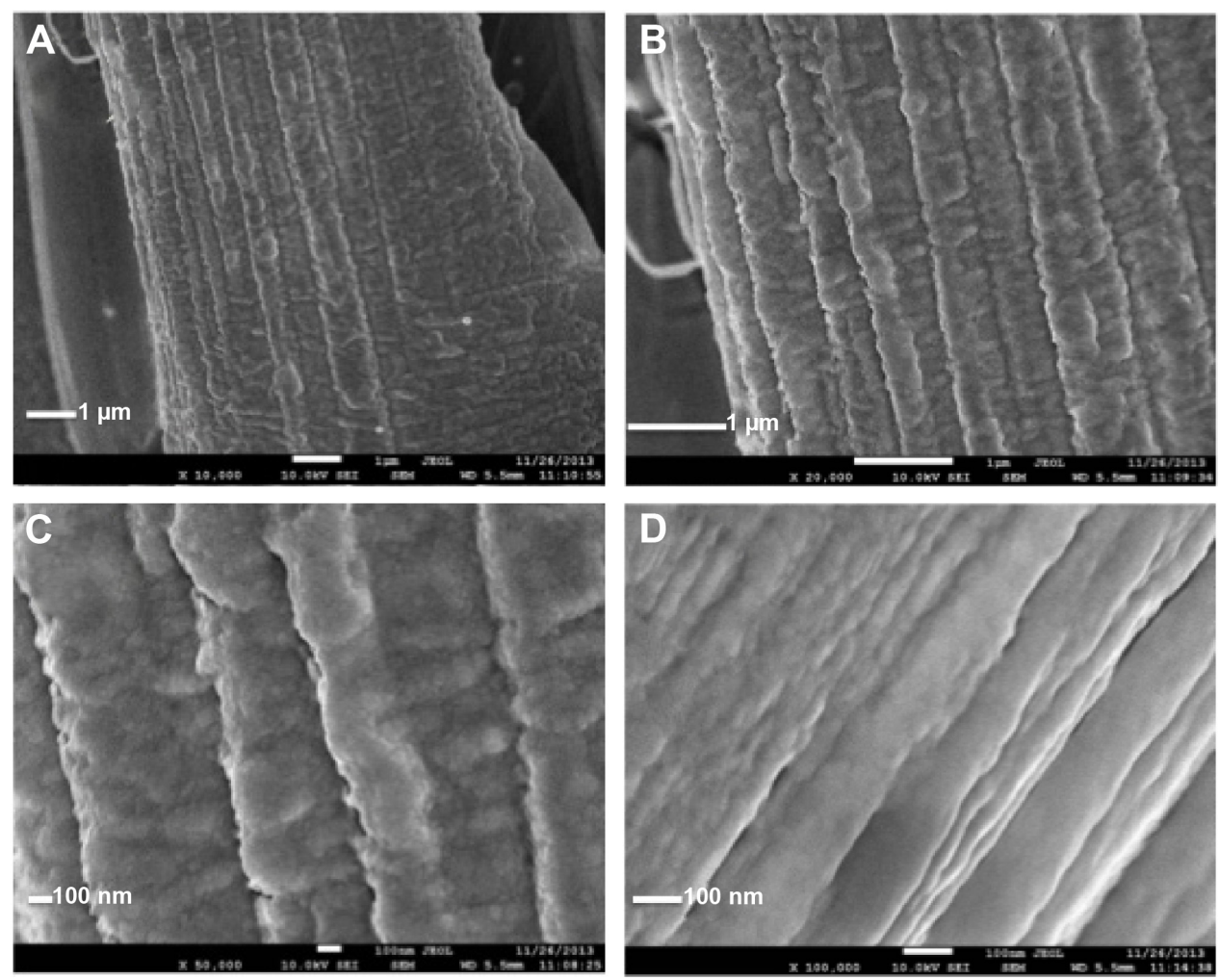

Figure 3 FESEM images at increasing magnification of Au deposited by PLD with 50,000 laser pulses onto WOx.

Notes: The images are taken at different magnifications as shown by the scale bars (A-D), from the same location.

Abbreviations: FESEM, field emission scanning electron microscopy; PLD, pulsed laser deposition; WOx, tungsten oxide. 
A

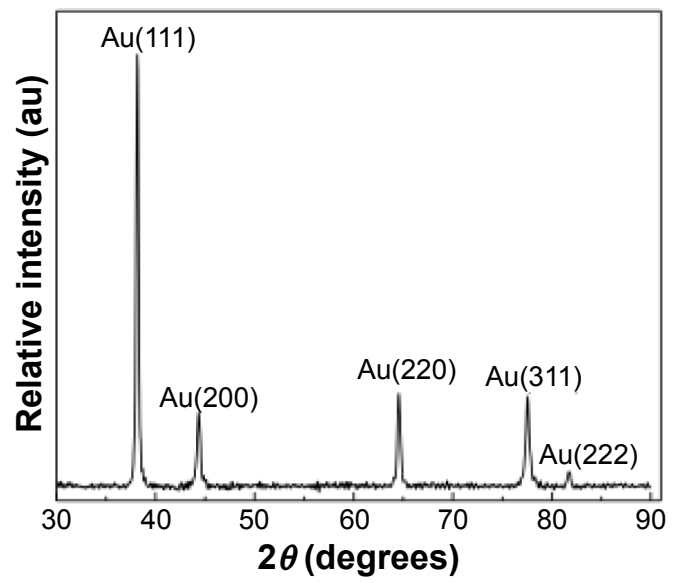

B

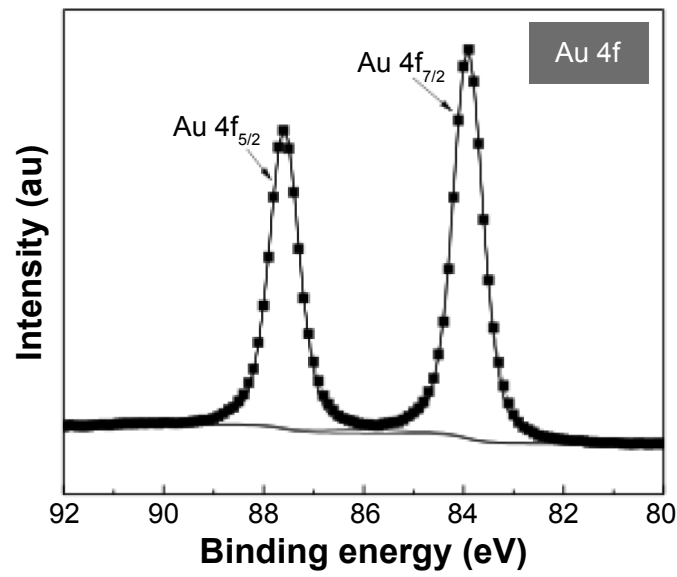

Figure 4 Surface analyses of Au deposited by PLD onto WOx.

Notes: (A) XRD and (B) high-resolution XPS spectrum of the Au 4f region of PLD deposited Au with 50,000 laser pulses onto WOx. Abbreviations: PLD, pulsed laser deposition; WOx, tungsten oxide; XPS, X-ray photoelectron spectroscopy; XRD, X-ray diffraction.
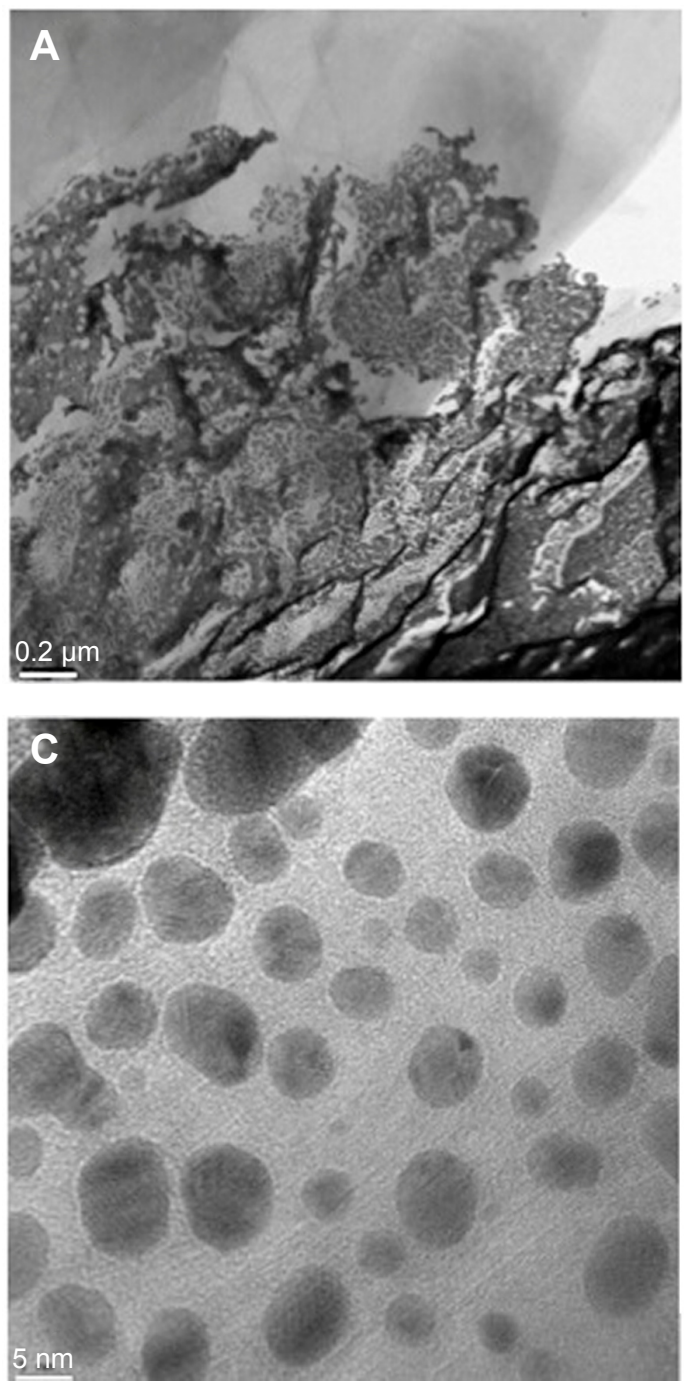
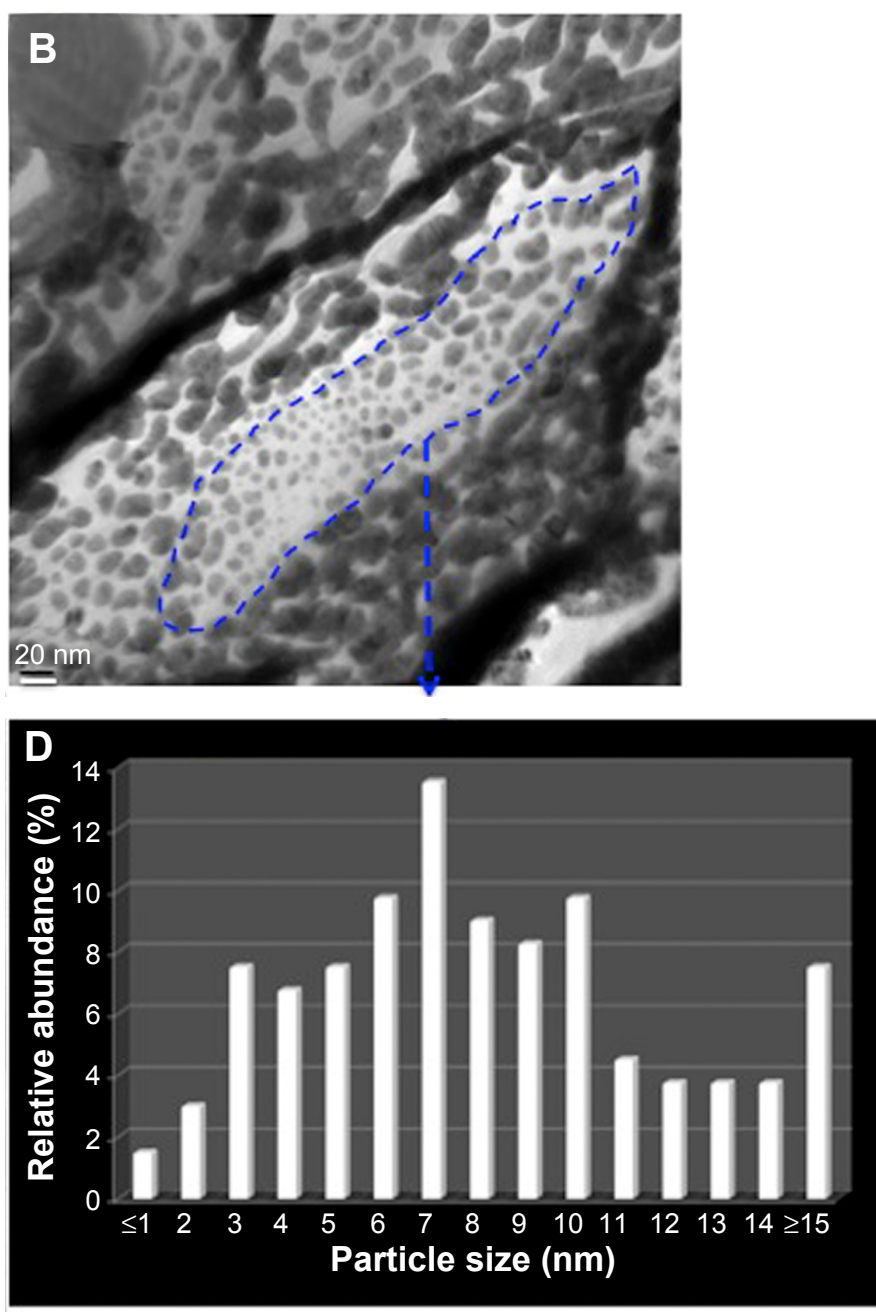

Figure 5 Analyses of Au deposited by PLD.

Notes: (A and B) TEM and (C) HR-TEM analyses of Au deposited by PLD. (D) Particle size distribution.

Abbreviations: HR-TEM, high-resolution transmission electron microscopy; PLD, pulsed laser deposition; TEM, transmission electron microscopy. 
A

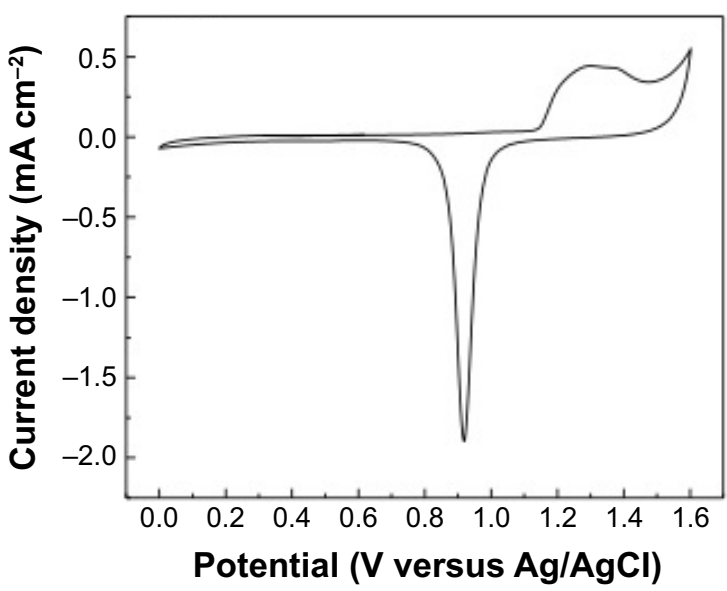

B

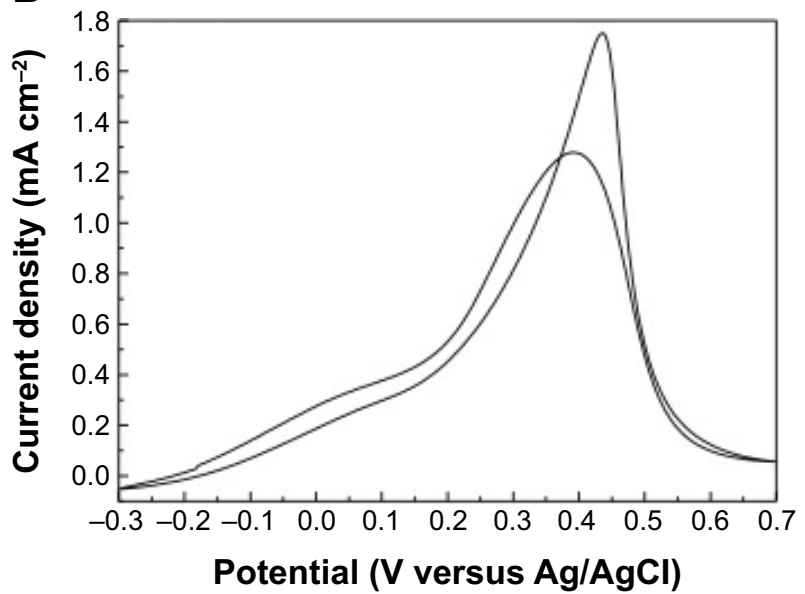

Figure 6 Cyclic voltammetry at Au deposited onto WOx.

Notes: (A) Recorded with $50 \mathrm{mV}$ second ${ }^{-1}$ potential scan rate in a deaerated solution of $0.5 \mathrm{M} \mathrm{H}_{2} \mathrm{SO}_{4}$. (B) Recorded with $2 \mathrm{mV}$ second ${ }^{-1}$ potential scan rate in argonsaturated $0.01 \mathrm{M}$ phosphate-buffered saline solution at $\mathrm{pH} 7.2$ containing $100 \mathrm{mM}$ of glucose.

Abbreviation: WOx, tungsten oxide.

of about $2.0 \mathrm{~cm}^{2}$ was estimated by integrating the charge consumed for reducing the Au oxides formed in the positive scan by assuming that the reduction of a monolayer of $\mathrm{Au}$ oxides requires $400 \mu \mathrm{C} \mathrm{cm}^{-2} .40$

Afterwards, CV was initially employed to characterize the GER at the WOx/Au electrode. Figure 6B shows a CV recorded at a slow scan rate of $2 \mathrm{mV} \mathrm{s}^{-1}$ (quasi-steady state) in a pH 7.2 PBS solution containing $100 \mathrm{mM}$ of glucose. The electrode revealed the distinctive response of GER at Au electrode.$^{41}$ The peak current density in the forward scan equals $1.28 \mathrm{~mA} \mathrm{~cm}^{-2}$, and the onset potential at which the GER starts is as negative as $-0.3 \mathrm{~V}$ versus $\mathrm{Ag} / \mathrm{AgCl}$.

Electrochemical techniques such as $\mathrm{CV}$, chronoamperometry, and SWV were used to investigate the sensing properties toward glucose at various concentrations. Results obtained with $\mathrm{CV}$ and chronoamperometry are presented in Figures S3 and S4, respectively. In the following, only results obtained with SWV are discussed because this technique yielded to better sensitivity as compared to the two former electrochemical techniques. This is expected because the SWV technique is a pulse method, allowing differentiating between the capacitive currents and the faradaic process mainly at very low concentrations of the analyte, and the acquisition time is faster. ${ }^{42}$

Figure 7A shows SWVs recorded under optimized conditions, ie, frequency of $20 \mathrm{~Hz}$, square-wave amplitude of $20 \mathrm{mV}$, and step potential of $1 \mathrm{mV}$ in $0.01 \mathrm{M} \mathrm{pH} \mathrm{7.2} \mathrm{PBS}$ solution containing various concentrations of glucose varying from $10 \mu \mathrm{M}$ to $100 \mathrm{mM}$. Well-defined SWV peaks were obtained. It can be seen that the peak current increases as the concentration of glucose increases (Figure 7B). A linear relationship with a regression equation of $\mathrm{y}=65.7 \mathrm{x}-1.7$ (x: concentration $/ \mathrm{mM}$, y: current $/ \mu \mathrm{A} \mathrm{cm}^{-2}$ ) and a correlation coefficient of $R^{2}=0.9974$ was observed from $10 \mu \mathrm{M}$ to $10 \mathrm{mM}$ (Figure 7C), which is far beyond the physiological level (3-8 mM). For glucose concentrations higher than $10 \mathrm{mM}$, a nonlinear dependence was noticed because of the saturation of the active adsorption sites with glucose. The sensitivity was found to be $65.7 \mu \mathrm{A} \mathrm{cm}^{-2} \mathrm{mM}^{-1}$, and a low detection limit of $10 \mu \mathrm{M}$ was reached with a signal/noise ratio higher than 3 .

The sensitivity obtained with the SWV technique was far greater than that measured by $\mathrm{CV}\left(30.8 \mu \mathrm{A} \mathrm{cm}^{-2} \mathrm{mM}^{-1}\right)$ and chronoamperometry $\left(24.5 \mu \mathrm{A} \mathrm{cm}^{-2} \mathrm{mM}^{-1}\right)$. The sensitivity achieved with the WOx/Au electrode was greater than that attained at $\mathrm{CP} / \mathrm{Au}\left(3.6 \mu \mathrm{A} \mathrm{cm}^{-2} \mathrm{mM}^{-1}\right)$ (unpublished results), $\mathrm{CNT} / \mathrm{Au}\left(25 \mu \mathrm{A} \mathrm{cm}^{-2} \mathrm{mM}^{-1}\right),{ }^{17} \mathrm{CNT} / \mathrm{AuOx}\left(43.6 \mu \mathrm{A} \mathrm{cm}^{-2}\right.$ $\left.\mathrm{mM}^{-1}\right),{ }^{18} \mathrm{CeO}_{2} / \mathrm{Au}\left(44 \mu \mathrm{A} \mathrm{cm}^{-2} \mathrm{mM}^{-1}\right),{ }^{20}$ and codeposited $\mathrm{CeO}_{2} / \mathrm{Au}\left(57.5 \mu \mathrm{A} \mathrm{cm}^{-2} \mathrm{mM}^{-1}\right){ }^{21}$

\section{Conclusion}

In summary, the PLD technique was employed to fabricate WOx thin film on $\mathrm{CP}$ by ablating metallic $\mathrm{W}$ in the presence of $1.33 \mathrm{~Pa}$ of oxygen. Both Micro-Raman spectroscopy and TEM revealed that the grown WOx is amorphous and made of ultrafine particles of subnanometer size. XPS analysis showed that the deposited WOx was three different oxidation states, $\mathrm{W}^{4+}, \mathrm{W}^{5+}$, and $\mathrm{W}^{6+}$, close to the structure $\mathrm{W}_{18} \mathrm{O}_{49}$.

Afterwards, Au nanoparticles were deposited by PLD onto WOx. Both XRD and XPS showed that only metallic $\mathrm{Au}$ was present at the surface of the WOx/Au composite, 
A

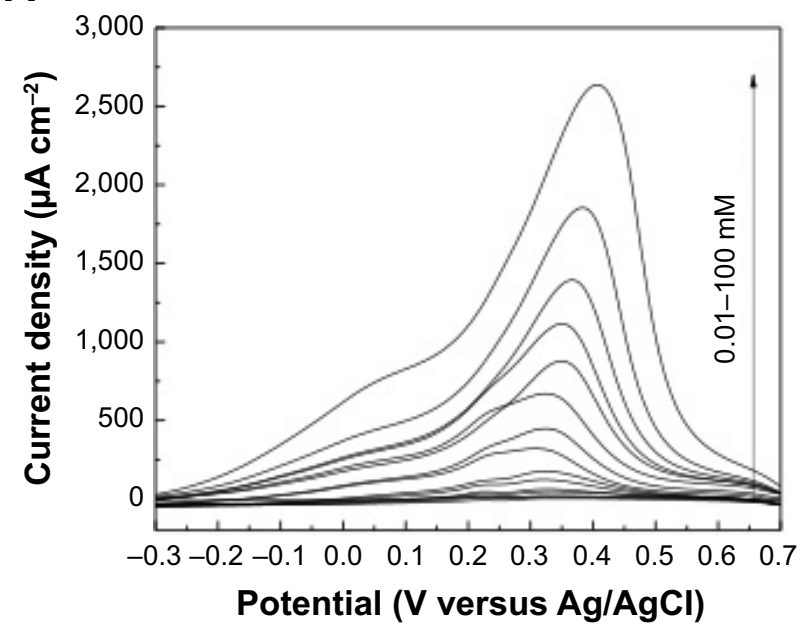

B

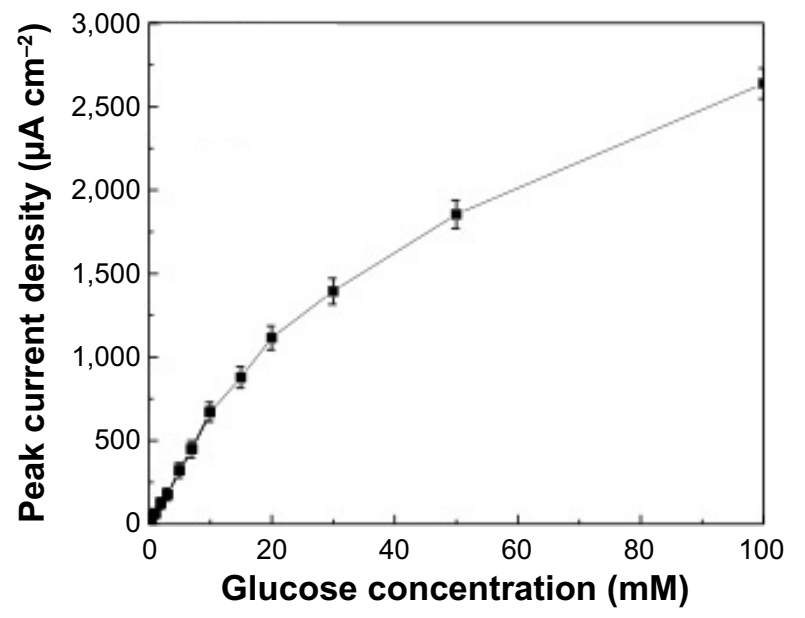

C

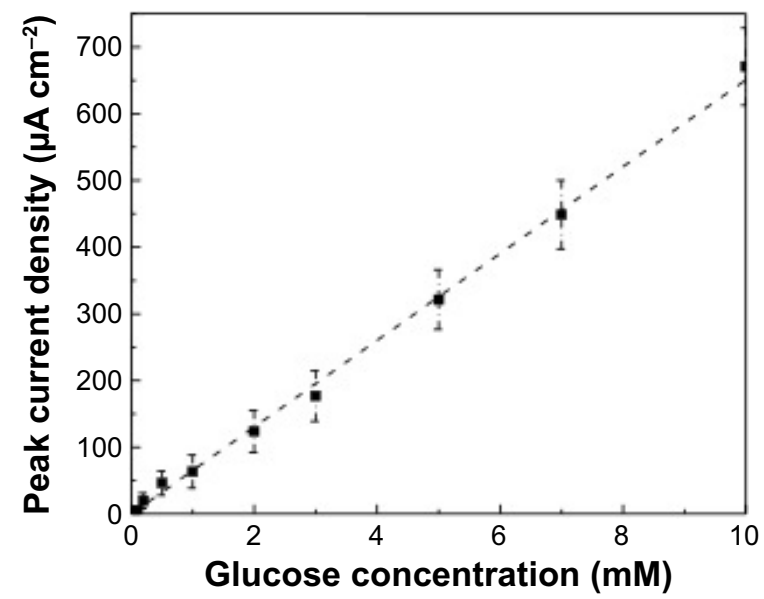

Figure 7 Electrochemical studies of glucose detection and sensitivity.

Notes: (A) Square-wave voltammograms recorded with an amplitude of $20 \mathrm{mV}$, a step potential of I mV, and a frequency of $20 \mathrm{~Hz}$ at the WOx/Au electrode in argonsaturated $0.01 \mathrm{M}$ phosphate-buffered saline solution at $\mathrm{pH} 7.2$ containing concentrations of glucose varying from $0.1 \mathrm{mM}$ to $100 \mathrm{mM}$. (B) The dependence of the peak current of the glucose oxidation on the concentration of glucose. (C) The obtained linearity domain up to $10 \mathrm{mM}$ of glucose.

Abbreviation: WOx, tungsten oxide.

suggesting that the WOx support did not alter the electronic structure of Au. It is observed, however, that the presence of WOx in the $\mathrm{C} / \mathrm{Au}$ catalyst gives rise to coalescence during the formation of the Au catalyst particle, which results in a particle size larger than previously observed of Au deposited onto CNT or onto $\mathrm{CeO}_{2}$ supports. Then, under the synthesis conditions used in this work, the presence of WOx in the $\mathrm{C} / \mathrm{Au}$ catalyst affects the morphological characteristics of the Au catalyst.

The electrocatalytic properties of the WOx/Au composite toward GER were investigated at different concentrations of glucose in PBS solution. It was demonstrated that such composite possessed high catalytic activity toward GER and delivered a sensitivity for glucose oxidation as high as $65.7 \mu \mathrm{A} \mathrm{cm}^{-2} \mathrm{mM}^{-1}$ within a $10 \mu \mathrm{M}$ to $10 \mathrm{mM}$ range and a low detection limit of $10 \mu \mathrm{m}$ of glucose.
This interesting analytical performance makes the laserfabricated $\mathrm{Au} / \mathrm{WOx}$ nanocomposite electrode potentially promising for glucose fuel cells, for biomedical analysis like the determination of glucose concentration in biological fluids, such as blood saliva, sweat, urine, and serum, as well as for food and beverage analysis.

Although this is the first work that reports the use of WOx as catalyst support for Au toward glucose oxidation with high sensitivity, we believe the electrochemical performance of the electrode can be improved further by optimizing the growth condition of WOx, such as its morphology (smoothness versus porosity), structure (amorphicity versus crystallinity), and thickness, the nature of the background atmosphere and pressure, or the simultaneous deposition of WOx and Au. Such systematic study will further answer the question of whether the improved GER activity of Au is due 
to cocatalytic properties of WOx or simply due to the modification of the morphological properties of Au by WOx.

\section{Acknowledgment}

This work was financially supported by the Natural Sciences Engineering Research Council of Canada and the Fonds Québécois pour la Recherche en Nature et Technologie.

\section{Disclosure}

The authors report no conflicts of interest in this work.

\section{References}

1. Zhang Z, Liu J, Gu J, Su L, Cheng L. An overview on metal oxide materials as electrocatalysts and supports for polymer electrolyte fuel cells. Energy Environ Sci. 2014;7:2535-2558.

2. Singh K, Nowotny J, Thangadurai V. Amphoteric oxide semiconductors for energy conversion devices: a tutorial review. Chem Soc Rev. 2013; 42(5):1961-1972.

3. Nuraje N, Asmatulu R, Kudaibergenov S. Metal oxide-based functional materials for solar energy conversion: a review. Current Inorganic Chemistry. 2012;2(2):124-146.

4. Ren Y, Ma Z, Bruce PG. Ordered mesoporous metal oxides: synthesis and applications. Chem Soc Rev. 2012;41(14):4909-4927.

5. Bellino MG, Soler-Illia GJ. Nano-designed enzyme-functionalized hierarchical metal-oxide mesoporous thin films: en route to versatile biofuel cells. Small. 2014;10(14):2834-2839, 2743.

6. Pasta M, La Mantia F, Cui Y. Mechanism of glucose electrochemical oxidation on gold surface. Electrochim Acta. 2010;55(20):5561-5568.

7. Cosnier S, Le Goff A, Holzinger M. Towards glucose biofuel cells implanted in human body for powering artificial organs: review. Electrochem Commun. 2014;38:19-23.

8. Chen C, Xie Q, Yang D, et al. Recent advances in electrochemical glucose biosensors: a review. RSC Adv. 2013;3:4473-4491.

9. Monosik R, Stredansky M, Tkac J, Sturdik E. Application of enzyme biosensors in analysis of food and beverages. Food Anal Methods. 2012;5(1):40-53.

10. Zhang G. Functional gold nanoparticles for sensing applications Nanotechnology Reviews. 2013;2(3):269-288.

11. Ben Aoun S, Size-controlled electrocatalysis of glucose oxidation in an alkaline solution at AuNPS electrodeposited onto glassy carbon electrodes. Int J Electrochem Sci. 2013;8:10454-10460.

12. Guerra-Balcázar M, Ortega R, Castaneda F, Arriaga GL, Ledesma-Garcia J. Synthesis of Au nanoparticles/polyaniline composites by electroreduction for glucose oxidation. Int J Electrochem Sci. 2011;6:4667-4675.

13. Seo B, Kim J. Electrooxidation of glucose at nanoporous gold surfaces: structure dependent electrocatalysis and its application to amperometric detection. Electroanalysis. 2010;22(9):939-945.

14. Liu A, Ren Q, Xu T, Yuan M, Tang W. Morphology-controllable gold nanostructures on phosphorus doped diamond-like carbon surfaces and their electrocatalysis for glucose oxidation. Sens Actuators B Chem. 2012; 162(1):135-142.

15. Wang Q, Min F, Zhu J. Preparation of gold nanowires and its application in glucose biosensing. Mater Lett. 2013;91:9-11.

16. Sebez B, Su L, Ogorevc B, Tong Y, Zhang X. Aligned carbon nanotube modified carbon fibre coated with gold nanoparticles embedded in a polymer film: voltammetric microprobe for enzymeless glucose sensing. Electrochem Commun. 2012;25:94-97.

17. Gougis M, Tabet-Aoul A, Ma D, Mohamedi M. Laser synthesis and tailor-design of nanosized gold onto carbon nanotubes for non-enzymatic electrochemical glucose sensor. Sens Actuators B Chem. 2014; 193:363-369.

18. Gougis M, Pereira A, Ma D, Mohamedi M. Oxygen gas assisted laser deposition of gold thin films: electrooxidation of glucose. Int $J$ Electrochem Sci. 2014;9:3588-3601.
19. Xu S, Yao Y, Wang P, et al. Anodic fabrication of nanoporous gold films from pure gold in oxalic acid solution and their applications in electrocatalysis and SERS. Int J Electrochem Sci. 2013;8:1863-1870.

20. Tian K, Prestgard M, Tiwari A. A review of recent advances in nonenzymatic glucose sensors. Mater Sci Eng C Mater Biol Appl. 2014;41: $100-118$.

21. Gougis M, Tabet-Aoul A, Ma D, Mohamedi M. Nanostructured cerium oxide catalyst support: effects of morphology on the electroactivity of gold toward oxidative sensing of glucose. Microchim Acta. 2014;181: $1207-1214$.

22. Gougis M, Pereira A, Ma D, Mohamedi M. Simultaneous deposition of cerium oxide and gold nanostructures-characterization and analytical properties toward glucose electro-oxidation and sensing. RSC Adv. 2014;4:39955-39961.

23. Santato C, Odziemkowski M, Ulmann M, Augustynski J. Crystallographically oriented mesoporous WO3 films: synthesis, characterization, and applications. J Am Chem Soc. 2001;123(43): 10639-10649.

24. Granqvist CG, Electrochromic tungsten oxide films: review of progress 1993-1998. Solar Energy Materials and Solar Cells. 2000;60(3): 201-262.

25. Baeck SH, Choi KS, Jaramillo TF, Stucky GD, McFarland EW. Enhancement of photocatalytic and electrochromic properties of electrochemically fabricated mesoporous $\mathrm{WO}_{3}$ thin films. Adv Mater. 2003;15(5):1269-1273.

26. Solis JL, Saukko S, Kish L, Granqvist CG, Lantto V. Semiconductor gas sensors based on nanostructured tungsten oxide. Thin Solid Films. 2001;391(2):255-260.

27. Qu W, Wlodarski W. A thin-film sensing element for ozone, humidity and temperature. Sens Actuators B Chem. 2000;64(1-3):42-48.

28. Yoon S, Jo C, Noh SY, Lee CW, Song JH, Lee J. Development of a high-performance anode for lithium ion batteries using novel ordered mesoporous tungsten oxide materials with high electrical conductivity. Phys Chem Chem Phys. 2011;13(23):11060-11066.

29. Yoon S, Kang E, Kim JK, Lee CW, Lee J. Development of highperformance supercapacitor electrodes using novel ordered mesoporous tungsten oxide materials with high electrical conductivity. Chem Commun (Camb). 2011;47(3):1021-1023.

30. Chrisey DB, Hubler GK. Pulsed Laser Deposition of Thin Films. New York, NY: John Wiley \& sons, Inc.; 1994.

31. Boulova M, Lucazeau G. Crystallite nanosize effect on the structural transitions of $\mathrm{WO}_{3}$ studied by Raman spectroscopy. J Solid State Chem. 2002;167(2):425-434.

32. Lethy KJ, Beena D, Vinod Kumar R, et al. Nanostructured tungsten oxide thin films by the reactive pulsed laser deposition technique. Appl Phys A. 2008;91:637-649.

33. Di Fonzo F, Bailini A, Russo V, et al. Synthesis and characterization of tungsten and tungsten oxide nanostructured films. Catal Today. 2006;116(1):69-73.

34. Cross WB, Parkin IP. Aerosol assisted chemical vapour deposition of tungsten oxide films from polyoxotungstate precursors: active photocatalysts. Chem Commun (Camb). 2003;(14):1696-1697.

35. Lee S, Cheong HM, Tracy CE, Mascarenhas A, Benson DK, Deb SK. Raman spectroscopic studies of electrochromic a- $\mathrm{WO}_{3}$. Electrochim Acta. 1999;44(18):3111-3115.

36. Ingham B, Chong SV, Tallon JL. Layered tungsten oxide-based organicinorganic hybrid materials: an infrared and Raman study. JPhys Chem B. 2005;109(11):4936-4940.

37. Pfeifer J, Guifang C, Tekula-Buxbaum P, Kiss BA, Farkas-Jahnke M, Vadasdi K. A reinvestigation of the preparation of tungsten oxide hydrate $\mathrm{WO}_{3}, 1 / 3 \mathrm{H}_{2} \mathrm{O}$. J Solid State Chem. 1995;119(1): 90-97.

38. Green SV, Kuzmin A, Purans J, Granqvist CG, Niklasson GA. Structure and composition of sputter-deposited nickel-tungsten oxide films. Thin Solid Films. 2011;519(7):2062-2066.

39. De Angelis BA, Schiavello M. X-ray photoelectron spectroscopy study of nonstoichiometric tungsten oxides. J Solid State Chem. 1977;21(1):67-72. 
40. Seah MP, Smith GC, Anthony MT. AES: Energy calibration of electron spectrometers. I - an absolute, traceable energy calibration and the provision of atomic reference line energies. Surf Interface Anal. 1990;15(5):293-308.

41. Angerstein-Kozlowska H, Conway BE, Hamelin A, Stoicoviciu L. Elementary steps of electrochemical oxidation of single-crystal planes of $\mathrm{Au}$ Part II. A chemical and structural basis of oxidation of the (111) plane. J Electroanal Chem Interfacial Electrochem. 1987;228(1-2):429-453.
42. Cheng TM, Huang TK, Lin HK, et al. (110)-exposed gold nanocoral electrode as low onset potential selective glucose sensor. ACS Appl Mater Interfaces. 2010;2(10):2773-2780.

43. Lovric M. Guide to experiments and applications. In: Scholz F, editor. Electroanalytical Methods: Guide to Experiments and Applications. Berlin, Germany: Springer-Verlag; 2009:121-143. 


\section{Supplementary materials}

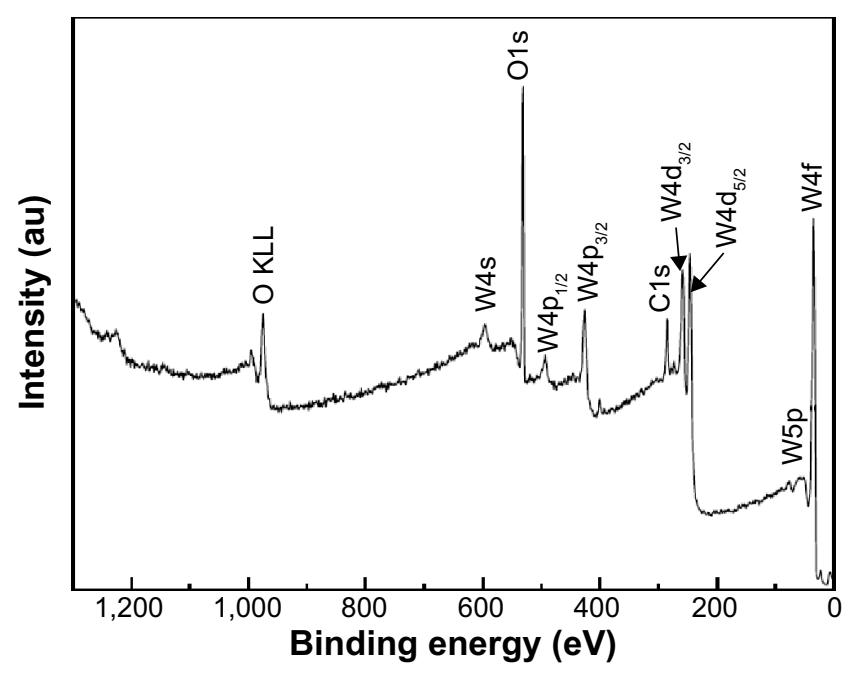

Figure SI XPS survey scan of WOx deposited onto carbon paper.

Abbreviations: XPS, X-ray photoelectron spectroscopy; WOx, tungsten oxide.

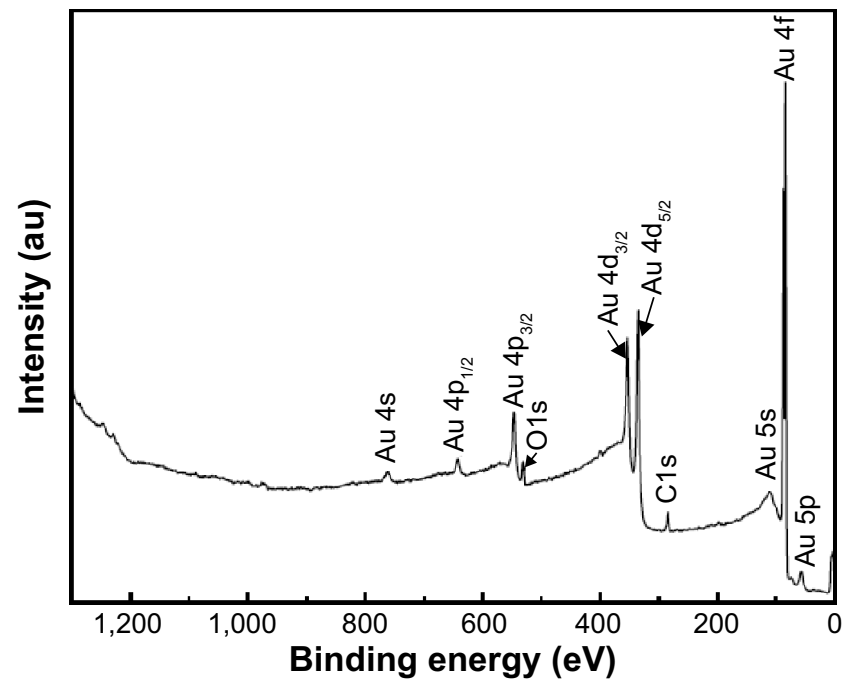

Figure S2 XPS survey scan of Au deposited onto WOx.

Abbreviations: WOx, tungsten oxide; XPS, X-ray photoelectron spectroscopy.
A

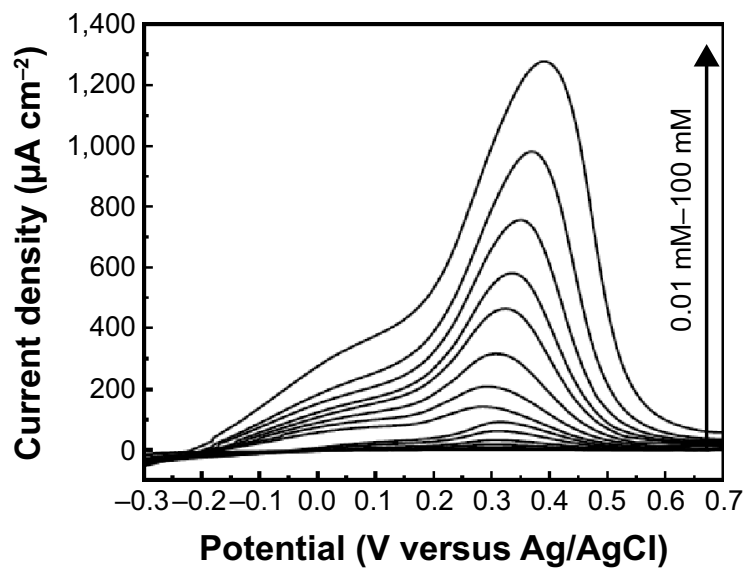

B

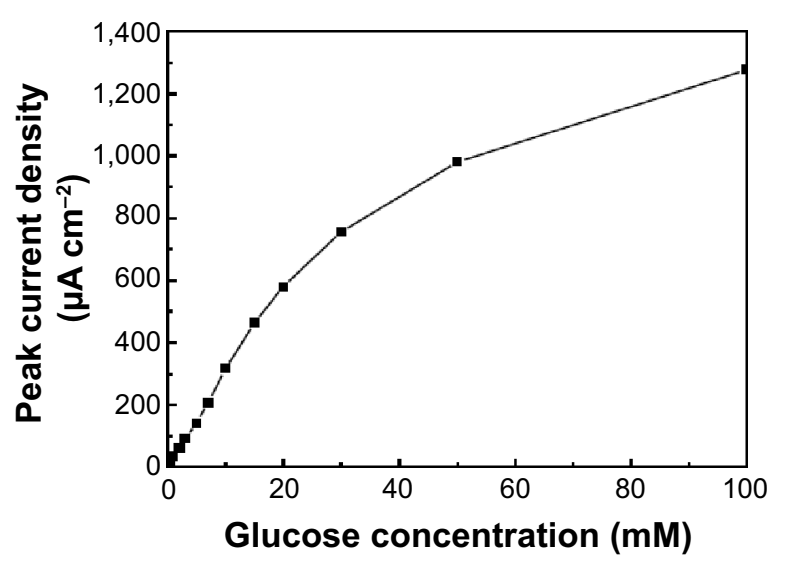

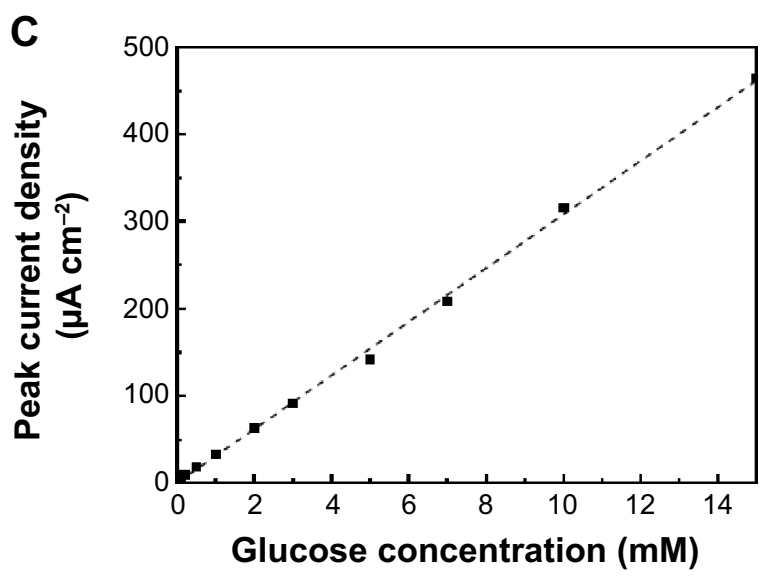

Figure S3 Electrochemical studies of glucose detection and sensitivity.

Notes: (A) Voltammetry measurements recorded with $2 \mathrm{mV}$ second ${ }^{-1}$ at the Au-WOx electrode in argon-saturated $0.01 \mathrm{M}$ PBS solution at pH 7.2 containing concentrations of glucose varying from $0.01 \mathrm{mM}$ to $100 \mathrm{mM}$; (B) the dependence of the peak current density over the whole range of glucose concentration and (C) the linearity domain of peak current density. A linear relationship with a regression equation of $y=30.8 \times+0.34\left(\times\right.$ : concentration $/ \mathrm{mM}, y$ : current $\left./ \mu \mathrm{A} \mathrm{cm}{ }^{-2}\right)$ and a correlation coefficient of $R^{2}=0.9987$ was observed from $10 \mu \mathrm{M}$ to $15 \mathrm{mM}$ (C). The sensitivity was found to be $30.8 \mu \mathrm{A} \mathrm{cm}^{-2} \mathrm{mM}^{-1}$ and a low detection limit $10 \mu \mathrm{M}$.

Abbreviations: WOx, tungsten oxide; PBS, phosphate-buffered saline. 
A

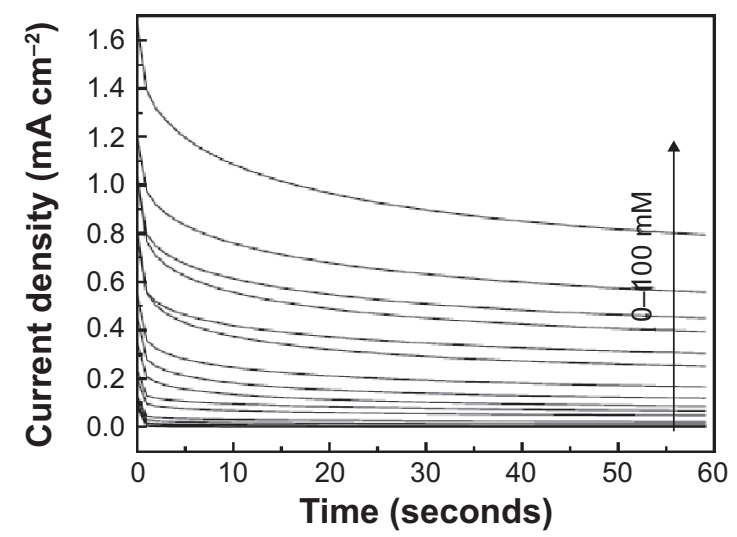

B

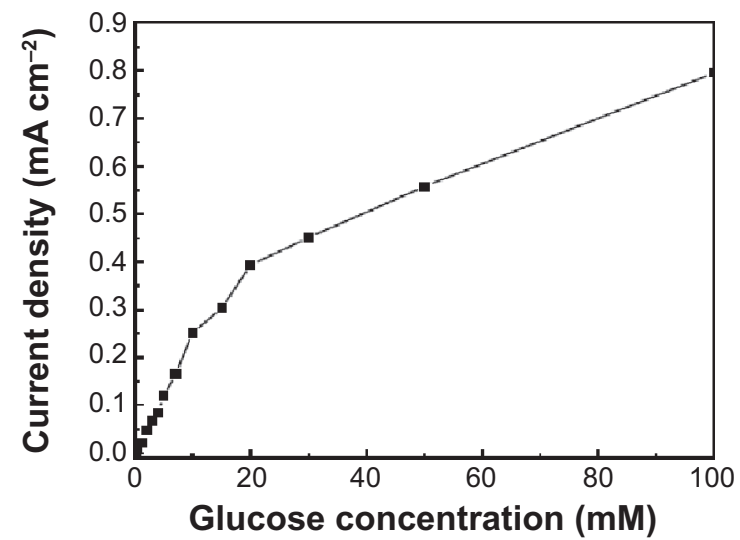

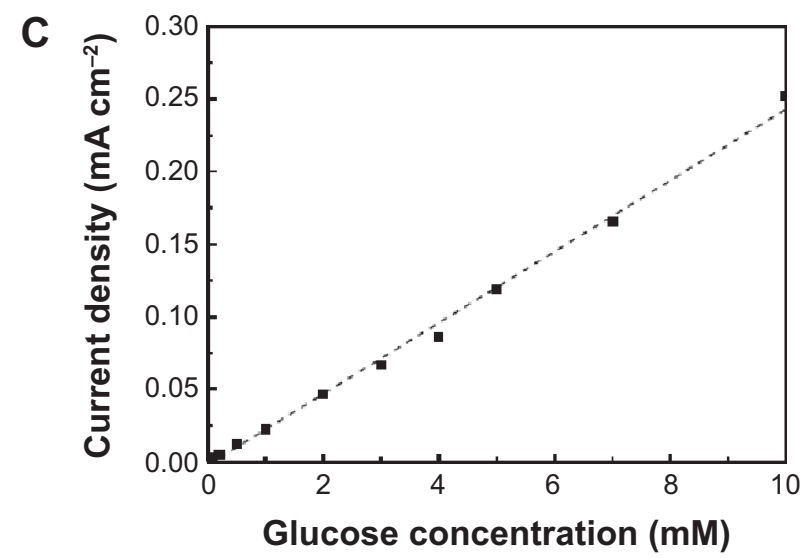

Figure S4 Electrochemical studies of glucose detection and sensitivity.

Notes: (A) Chronoamperometry measurements at an applied potential of $0.25 \mathrm{~V}$ vs $\mathrm{Ag} / \mathrm{AgCl}$ at the Au-WOx electrode in argon-saturated $0.0 \mathrm{I} \mathrm{M}$ PBS solution at $\mathrm{pH} 7.2$ containing concentrations of glucose varying from $0 \mathrm{mM}$ to $100 \mathrm{mM}$; (B) the dependence of the steady-state current density over the whole range of glucose concentration and $(\mathbf{C})$ the linearity domain of the steady-state current density. A linear relationship with a regression equation of $y=24.5 \times-2.1\left(\times:\right.$ concentration $/ \mathrm{mM}, \mathrm{y}$ : current $\left./ \mu \mathrm{A} \mathrm{cm} \mathrm{m}^{-2}\right)$ and a correlation coefficient of $R^{2}=0.996$ I was observed from $10 \mu M$ to $10 \mathrm{mM}(\mathbf{C})$. The sensitivity was found to be $24.5 \mu A \mathrm{~cm}^{-2} \mathrm{mM}{ }^{-1}$ and a low detection limit $10 \mu M$. Abbreviations: WOx, tungsten oxide; PBS, phosphate-buffered saline.

\section{Publish your work in this journal}

The International Journal of Nanomedicine is an international, peerreviewed journal focusing on the application of nanotechnology in diagnostics, therapeutics, and drug delivery systems throughout the biomedical field. This journal is indexed on PubMed Central, MedLine, CAS, SciSearch $®$, Current Contents ${ }^{\circledR} /$ Clinical Medicine,
Journal Citation Reports/Science Edition, EMBase, Scopus and the Elsevier Bibliographic databases. The manuscript management system is completely online and includes a very quick and fair peer-review system, which is all easy to use. Visit http://www.dovepress.com/ testimonials.php to read real quotes from published authors. 